\title{
Airborne and Ground Information for Lateral Spacing during Closely Spaced Parallel Approach Operations
}

\author{
Researchers: Vernol Battiste - NASA Ames Research Center \\ Sheila Holland-Bochow, \& Nancy H. Johnson, San Jose State University Foundation
}

The AILS (Airborne Information for Lateral Spacing) system can increase the efficiency of airports in Instrument Meteorological Conditions (IMC) by allowing independent, parallel approaches to runways as close as 2,500 feet. The proposed AILS system consists of advanced conflict detection algorithms, flight deck displays, resolution procedures, and a set of airspace procedures to assist with such closely-spaced, independent approaches to parallel runways. The goal of this research was to explore and resolve potential human factors issues that might arise if the AILS system were implemented. This study examined flight crew and ATC interactions during independent closely spaced approach operations (CSPA). Twelve B-747 flight crews conducted AILS approaches to parallel, closely spaced runways at Seattle-Tacoma airport. During 75\% of the approaches an aircraft blunder and breakout was conducted. Flight crew workload and performance data were collected using both objective and subjective assessment methodologies. However, ATC performance and workload data were not collected. Data from the study suggest that with appropriate airspace and flight deck systems, closely spaced approach operations can be conducted safely. However, additional research is needed to assess conditions where crews responded slowly to AILS alerts.

\section{Introduction}

At least 43 major airports in the United States have parallel runways that are in very close proximity to each other - less than 4,400 feet apart. During Visual Meteorological Conditions (VMC), when visual contact between aircraft is possible, airport capacity is greatly increased by having aircraft fly closely spaced parallel visual approaches. Under Instrument Meteorological Conditions (IMC), airports with runways closer than 4,400 feet are required to revert to a single runway operation or to run dependent approaches. Each of these traffic flows greatly reduces the number of landing aircraft, sometimes by as much as $50 \%$.

This study examined the operational implementation of an airborne system which would support closely spaced parallel approach operations at airports with parallel runway centerlines as close as 2,500 feet during IMC. Additionally, the study examined the system's requirements, both flight deck and ATC, that would support the implementation of closely spaced parallel approach operations at a major HUB airport.

\section{Overview of the AILS Concept}

The primary objective of the AILS concept is to enable safe independent approaches to parallel runways with runway spacing of at least 2,500 feet, through the development of concepts, procedures, and supporting technology. The AILS system provides multiple levels of alerting for aircraft that are on parallel approaches. This, along with a highly accurate navigation capability to keep aircraft in their assigned airspace along the approach, will allow the transfer of responsibility from the controller to the AILS system for alerting crews to blundering parallel approach traffic. The initial AILS concept was that Differential Global Positioning System (DGPS) would provide the accurate navigation required to perform these precision approaches and that Automatic Dependent Surveillance-Broadcast (ADS-B) would provide the technology to broadcast the position and other state information between aircraft on parallel approaches [1]. This concept was based on the idea that DGPS could be used to maintain aircraft within a narrow sector approach, referred to as the "rocket ship" geometry. The rocket ship concept incorporated much more stringent boundaries for acceptable lateral deviation from the extended runway centerline, much smaller than a two-dot deviation as defined by the conventional ILS localizer [2,3].

Due to an industry move towards the use of Instrument Landing System (ILS)-like approaches for Global Positioning System (GPS) landing systems, the AILS concept has advanced so that it 
can integrate with both the developing GPS approach systems and the conventional ILS [1]. With the conventional ILS approach, DGPS would provide the alerting systems with the precise positioning information required to perform the approach. With the GPS approach systems, DGPS would not only provide position information, but would also provide guidance on the approach. A review of all research performed on the "rocket ship" AILS approach system can be found in "The Flight Deck Perspective of the NASA Langley AILS Concept" $[3,4,5,6]$.

\section{An AILS Approach}

AILS requires procedural roles to be assumed both by the flight deck and Air Traffic Control (ATC). Aircraft will be alerted that AILS approaches are in progress through some means such as the Automatic Terminal Information System report. When an AILS approach is selected in the Flight Management System (FMS), the AILS system will perform an integrity test, and the crew will be alerted if the system is not operational. In that case, it would be the responsibility of the crew to alert the approach controller that they will not be able to participate in the AILS approaches due a system failure.

ATC will maintain separation $(1,000$ feet vertically or 3 miles radar separation) between aircraft until aircraft are established on the final approach course and cleared for the approach. No transfer of separation responsibility for traffic on the parallel runway will be required; with the approved onboard AILS monitoring and alerting algorithms, each approach stream will be treated as a parallel independent operation. ATC will retain responsibility for longitudinal separation in both parallel approach streams and with any other aircraft not on final approach.

In the current Ames simulation of the AILS concept, DGPS provides the alerting systems with the precise positioning information required to perform the conflict assessment. The conventional instrument landing system (ILS) provides guidance to the approaching aircraft. ADS-B enables the aircraft to broadcast their position and other state information, such as track and speed. Onboard alerting algorithms then use this information to evaluate the position of the aircraft in relation to its nominal path. When an aircraft is not properly maintaining its nominal path, the alerting algorithms determine how the deviation will impact the approach. When a collision threat is detected, the algorithms trigger alerts to both the aircraft causing the collision threat (invader) and the threatened aircraft (evader).

\section{AILS Alerts}

The AILS alerting algorithms are activated when an AILS aircraft is established on the localizer. The first interrogation of the airspace by the system is to determine if another aircraft is within close enough proximity to be considered an "AILS PAIR." Once the parallel traffic has been identified as a possible threat, the system begins its threat evaluation. It is possible for multiple aircraft to reach this status, but unlikely based on current longitudinal spacing requirements. Each independent system projects the current state information of its own aircraft and the pair forward for a finite time in the future to see if it will puncture a zone around the evader's projected position $[3,7,8]$. The protected zone consists of an elliptical protection area in the horizontal plans and a linear distance above and below the aircraft. This protection area is divided into 2 cautionary and 2 warning levels of alerts, the parameters of which are presented in Table 1. For a complete description of the AILS alerting algorithms refer to [3]. In the event that one aircraft strays from its

\begin{tabular}{|c|c|c|c|c|}
\hline PARAMETER & Level 1 & Level 2 & Level 3 & Level 4 \\
\hline Downrange (ft) & 5000 & 3500 & 3400 & 2500 \\
\hline Cross-range (ft) & 1800 & 1300 & 1250 & 900 \\
\hline $\begin{array}{l}\text { Alert zone above } \\
\text { (ft) }\end{array}$ & 1800 & 1300 & 1250 & 900 \\
\hline $\begin{array}{l}\text { Alert zone below } \\
(\mathrm{ft})\end{array}$ & 1800 & 1300 & 1250 & 900 \\
\hline Alert time (sec) & 30 & 22 & 21 & 16 \\
\hline
\end{tabular}

Table 1. AILS Alerting Parameters. 
approach course while under AILS protection, the AILS algorithms will provide either a caution or a warning depending on the severity of the deviation. A caution is intended first to alert the erring aircraft, or invader, so that it may correct its course, and then to the threatened aircraft, or evader, to alert it to the possibility of a spacing violation. A warning requires immediate execution of an emergency escape maneuver. If the blundering aircraft fails to maintain its path and the algorithms determine that it is a collision threat, the invader is issued an immediate, accelerating, climbing turn away from the parallel traffic. The evader is also issued the same maneuver if the algorithms determine that the maneuver is required. As time permits, the crew will contact ATC, who would resume separation responsibility provided the aircraft are diverging and there is separation between targets on the radar display, or as soon as practical if the above conditions are not met.

\section{AILS Displays and Enunciations}

The AILS system transitions between four states: armed (ready), active, cautions (2), and warnings (2). The first state presents an indication to the crew that the AILS system is functional and in a ready state. The Navigation Display (NAV Display) presents "AILS" in white letters in the bottom right corner when the approach has been selected in the FMS. The white text indicates that an integrity test has been conducted and confirms that the system is ready. When the crew activates the approach on the Mode Control Panel (MCP), this text is also presented on the Primary Flight Display (PFD). When the aircraft intercepts the ILS localizer and is established within 400 feet laterally of the extended runway centerline, the system changes from a ready state to an active state. It is at this time that the AILS algorithms begin to evaluate for threats. The AILS text on the NAV Display and PFD change from a white ready state to a green active state, see Figures 1 and 2. Additionally, a green breakout procedure direction arrow appears on the PFD and a green breakout procedure-heading bug appears on the NAV Display. If a pairing does not occur on the approach, the system would remain in this state until it reaches decision height (DH) of 400 feet above runway threshold. At this point, the AILS text turns to brown and the breakout guidance cues are removed from the PFD, since it is not advisable to perform the procedural turning climb at or below 400 feet altitude.

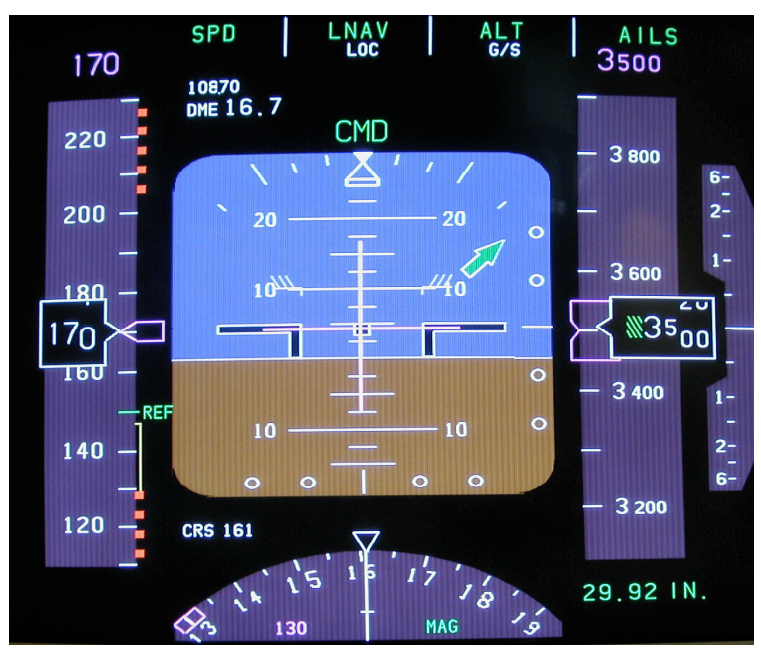

Figure 1. PFD With Green AILS Indication and Breakout Arrow.

If the system determines that the aircraft is within close enough proximity to another aircraft to be "paired," then the system will present a flight data tag on that aircraft fixed to the back opposite end of the aircraft symbol, see Figure 2. The tag presents the aircraft's call sign, and altitude, in addition to a climb/descent arrow. The color of the aircraft symbol and tag, in the non-alert state, follow the conventions of the NASA Ames CDTI [9]. Traffic that is above your own aircraft (ownship) by more than $700 \mathrm{ft}$ is presented in blue.

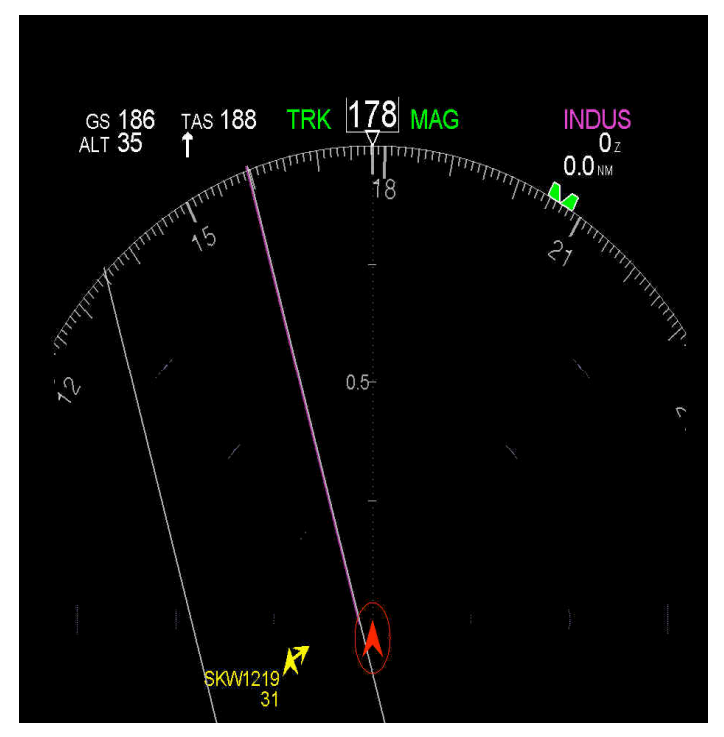

Figure 2. NAV Display With Green Heading Bug, and Ownship Breaking Out To Right.

Aircraft that are co-altitude $(+/-700 \mathrm{ft})$ are white. Traffic below (more than $700 \mathrm{ft}$ ) the ownship is 
presented in green. And finally, traffic on the airport surface is presented in brown. The altitude in the tag can be presented in either relative or absolute, and is based on the TCAS setting.

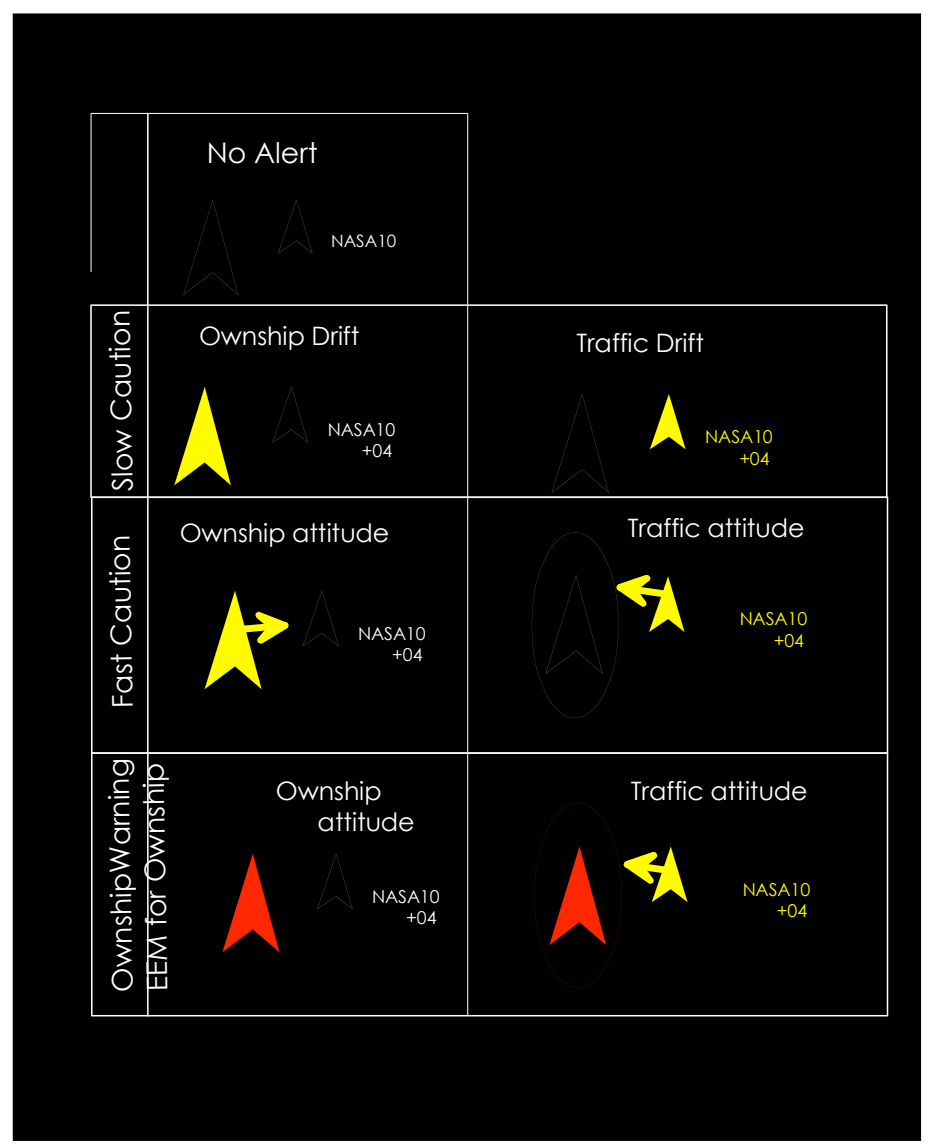

Figure 3. AILS Normal, Slow and Fast Cautions, and Breakout warnings (EEM).

For a Level 1 alert (PATH caution), the invader is provided an indication that he is straying from his nominal course. The caution is presented in two formats to provide the crew with some indication of the severity of their divergence from course. Either their symbol is changed to a filled yellow chevron or to a filled yellow chevron with an arrow. A filled symbol indicates that the aircraft has strayed from the localizer course by 200' feet. A filled amber chevron with an arrow in the direction of the parallel traffic, indicates that the aircraft is heading towards parallel approach traffic with a bank angle that will intersect the outer ellipse, see Figure 3. While this symbology is presented on the NAV Display, it is accompanied by a voice message of "Path" as well as an alphanumeric of "PATH" on the PFD in amber. This message format was not evaluated from the invaders' perspective in the study because a pseudo-aircraft was always the invader, while ownship (B747) was the evader. The alert symbology was, however, presented on the evaders' NAV Display.

For a Level 2 alert (TRAFFIC caution), the evader is provided information to help him prepare for an Emergency Escape Maneuver (EEM) if the alerting algorithms determine it is necessary. The evader's symbol for the parallel traffic turns to amber, either with or without an arrow depending on the criteria previously defined. The crew would also have the alphanumeric "TRAFFIC" presented on the PFD and the matching voice message.

An AILS Level 3 alert (Warning - EEM) indicates that corrective actions of the invader were not successful. The invader would receive instructions to perform an EEM at that time. The necessity to perform an EEM is indicated by changing the symbol of the evader to a red filled chevron. The PFD and voice warning system would announce "TURN, CLIMB" until a bank angle of 25 degrees was accomplished. Again, the solid filled chevron was momentarily presented on the evaders' NAV Display prior to receipt of the level 4 alert.

An AILS Level 4 alert (Warning - EEM) indicates to the evader that he must also break off the approach. The evader would then also see a change in his symbol from amber to red, as well as the "Turn, Climb" enunciation and presentation.

\section{The Emergency Escape Maneuver (EEM)}

The AILS breakout procedure was designed to provide a minimum level of separation of no less than 500 feet from the blundering parallel traffic. The 500 feet minimum was based on a criterion established during research on a controller-based parallel approach precision monitoring system (PRM) implemented by the FAA [10]. The AILS breakout procedure requires both prompt, correct responses and adherence to the published breakout procedure. Activation of an AILS warning on the NAV Display, a "CLIMB/TURN" on the PFD, or an aural "Climb, Turn" require execution of an AILS breakout procedure. The AILS breakout maneuver consists of a hand-flown procedure with flight director guidance. As the warning is issued, the flying pilot is to immediately engage "TOGA" power to either TOGA 1 or 2. Flight Director (FD) pitch and roll bars appear to command a climb and turn away from the approach course and away from the parallel approaching AILS traffic. The flying 
Figure 4. SEATAC Approach Control Airspace, Designed To Support Independent Closely Spaced Parallel AILS Approach Operations.

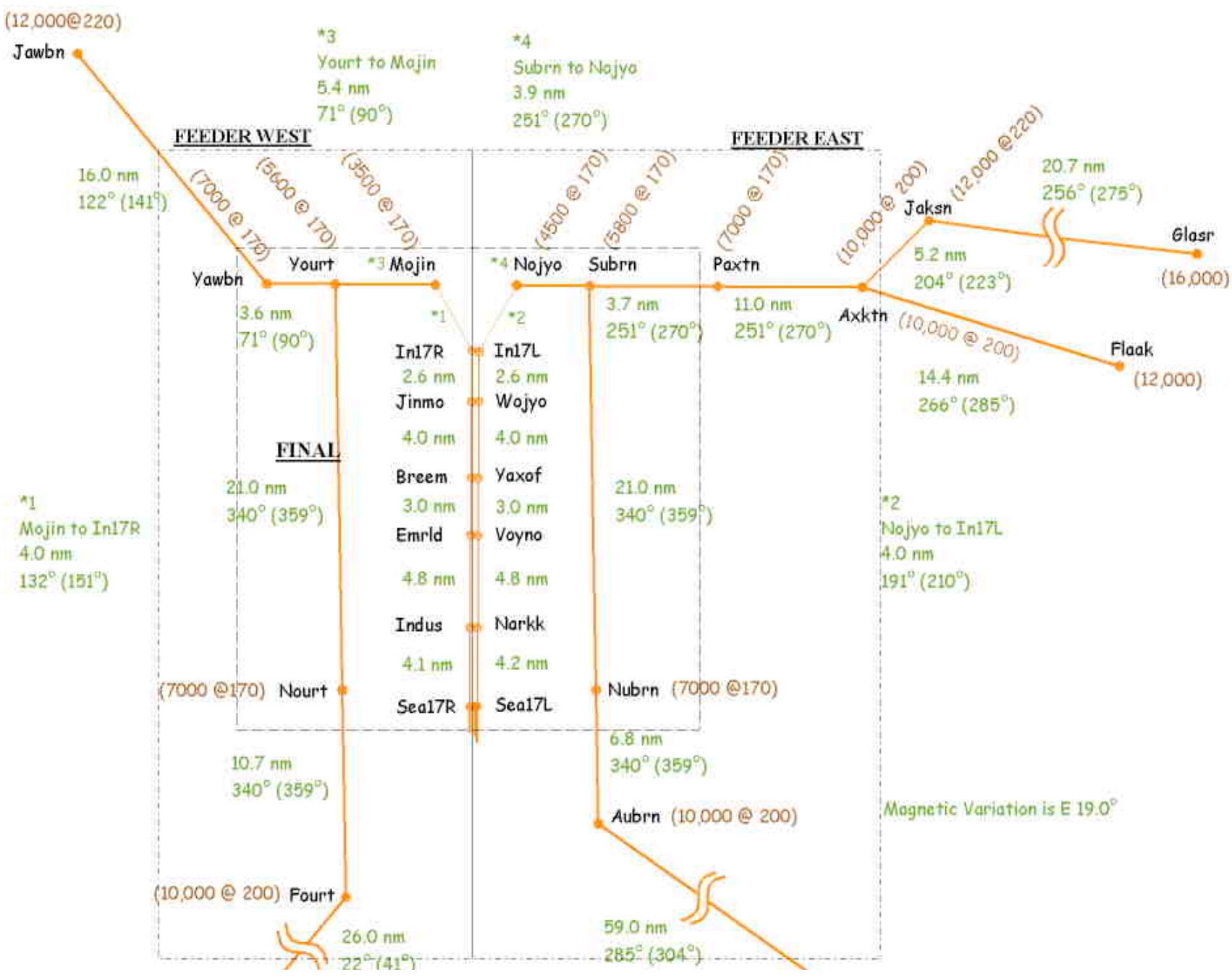

pilot is expected to promptly roll the aircraft to the FD's commanded bank angle of 25 degrees while simultaneously matching the FD's pitch command. FD pitch level is determined by level of TOGA activation and set speed. For any configuration an AILS breakout procedure requires an increased speed of fifteen $(+15)$ knots over current VREF.

\section{Study Goals}

The goal of this full mission simulation research was to address a number of operational questions that had not been fully addressed in previous AILS simulation research. The major questions to be addressed were related to crew and aircraft response time, transition of authority to and from the cockpit, and the impact of closely spaced parallel approach operations and multiple aircraft blunders on controllers and airspace operations at a major airport.

\section{Methods}

\section{Subjects}

Nine flight crews from two major airlines and two retired flight crewmembers participated in the study. All line crews were current B-747 qualified, and the retired crews had been retired less than one year. Flight crew experience ranged from 2,700 to 23,000 flight hours with a mean of 11,628 total flight hours. Flight crew experience in the B-747 ranged from 120 to 9,500 flight hours with a mean of 2,186 flight hours. All flight crews received the AILS training/familiarization packet prior to arriving for the study. The study was conducted in the NASA Ames Crew Vehicle Systems Research Facility (CVSRF), and utilized the level D certified B747 flight simulator and the ATC Lab. 


\section{DEMONSTRATION ONLY}

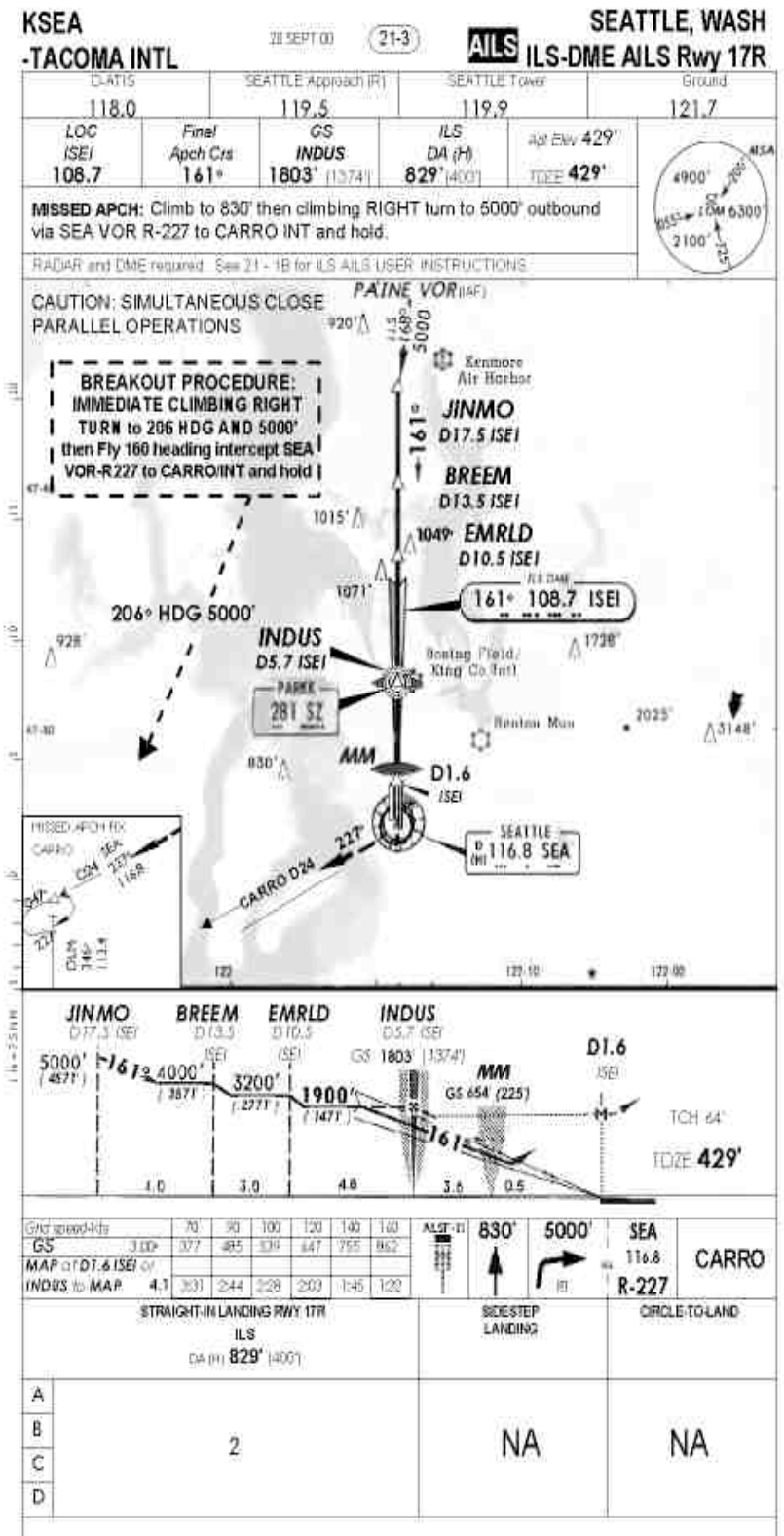

Figure 5. Approach Plate To Runway 17R, With Break-out Procedures.

\section{Independent Variables}

Blunder location and arrival runway were the only variables manipulated during the study. Captains and First Officers conducted approaches to runways 17 right and left at SEATAC and responded to blunders early, midway, and late during each approach. The early blunder occurred prior to glide slope intercept, or approximately 14 mile final. The mid-approach blunder occurred at approximately 7 mile final, after established on the glide slope, but prior to setting final flaps and gear.
The late blunder occurred around the outer marker, approximately 3 mile final, normally during final preparation for landing. The exact blunder locations could not be fixed because of the dynamic nature of the pairing algorithms.

\section{Scenarios}

In order to create a realistic work environment for the controllers in the study, four two-hour scenarios were created. The ownship was dynamically inserted into the scenario outside of the final controller's view. Each successful ownship insertion was referred to as a trial, and three trials were performed during each scenario, taking approximately one hour and 15 minutes.

The scenarios were based on a terminal area modeled on the Seattle-Tacoma (SEATAC) terminal area environment. While the current airport has a runway configuration of $800 \mathrm{ft}$ separation between runway centerlines, another runway is under construction $2500 \mathrm{ft}$. west and parallel to the existing runway $16 \mathrm{~L} / 34 \mathrm{R}$, fitting the criteria for the AILS procedure. The traffic for the four scenarios was obtained from arrival and departure traffic schedules provided by SEATAC. Additional traffic was added to increase the number of heavy jets expected to land at the airport, to help conceal the 747-400 simulator from the controller, and to maintain a traffic density of 48 arrivals an hour. This rate is consistent with normal traffic flow at SEATAC. Context traffic was released approximately 150 miles from the SEA VOR and approached in a normal four-corner post airspace configuration, while the ownship was released just outside the east and west feeder sector boundaries, outside of the final controller's view, in the northwest (JAWBN arrival) and the northeast (JAKSN arrival). Pseudo-pilots and the subject crew made initial contact with Seattle Approach Feeder Controllers upon entering the airspace.

Scenarios were created so that the aircraft could flow through the airspace without any intervention from a controller or pseudo-pilot. The context aircraft were scripted to fly from their release points and approximate the commands that would normally be given for their descent profiles on the arrival/approach, through the feeder and final sectors, and down to the runways. Prior to "working" the aircraft in the scenarios, the feeder controllers and pseudo-pilots were familiarized with the flow of traffic. The feeder controllers were instructed to maintain the initial flow of the 
scenario as closely as possible to preserve the pairing initially created in the scenario. In the feeders' airspace, all of the aircraft were removed from their scripts and flown manually by two pseudo-pilots. These pseudo-pilots were instructed to make their initial contact with Seattle approach control and wait for commands from the feeder controllers. If the feeder controller noted that the final controller was not able to work the number of aircraft being handed off, or that the streams of aircraft were becoming too dense, the feeder could apply normal ATC procedures to reduce or maintain the traffic flow, as they would normally. The feeder and final controllers, although not subjects in the study, were asked to conduct operations in the airspace based on normal operations at SEATAC. Pseudo-pilots were instructed to comply with all ATC clearances upon entering approach control airspace. Some of the pseudo-pilots, the feeder, and final controllers were retired air traffic controllers. The remaining pseudopilots were college students trained to perform the pseudo-pilot task.

\section{Airspace to Support AILS Operations}

Working with TRACON controllers from SEATAC, we constructed airspace and procedures that supported closely spaced parallel approach operations: altitude-constrained arrival paths, approaches, and breakout (missed approach) procedures.

To adequately protect closely spaced parallel approach traffic during a breakout maneuver, SEATAC controllers suggested the airspace and approach designs contained in Figure 4. The approach plate for each parallel runway provided information on the breakout procedure and the missed approach, which were coupled to provide a seamless transition to the missed approach point. The breakout procedure, 45 degree turn and climb to 5,000 feet, provided adequate room to maneuver away from invading traffic while remaining clear of northbound downwind arrival traffic at 6,000 feet. Additionally, if during a breakout a loss of communication occurred, or there was no contact with ATC, each aircraft would join the missed approach and proceed to its holding location, following its missed approach no-radio procedures (see Figure 5, approach plate to 17L). The approach plate and airspace designs all but eliminated the need to immediately contact ATC after a breakout, to provide separation from other terminal traffic.

\section{Tasks}

Flight Crews: Crews flew approximately 12 AILS approaches. They were instructed to conduct the approaches according to the rules provided in the supplemental ILS AILS Users Instructions, which were provided to the crews. In addition to the standard ILS instrument approach/landing briefing, the following ILS AILS approach procedures were added to the normal approach briefing: review ILS AILS approach chart, review the PF/PNF duties, and review the breakout procedure and any differences between missed approach and AILS breakout procedure, see Figure 4. The procedure also required that the ILS AILS approach was flown in autopilot to Decision Height (829 feet MSL). Additionally, the verbiage on the approach was modified to communicate clearly between the controllers and crews that AILS approaches were in progress and being performed. For example, crews were instructed to report to ATC that the aircraft was "AILS established" when the symbology on the PFD and NAV display changed from white to green once the aircraft was established on the localizer.

The AILS breakout procedure, although normally a rare event, was the primary task for flight crews in this study. The AILS breakout maneuver consists of a hand-flown procedure with FD guidance. As a warning is issued, the flying pilot is to immediately engage TOGA to either TOGA 1 or 2. FD pitch and roll bars appear commanding a climb and turn away from the approach course and away from the parallel AILS traffic. The flying pilot is expected to promptly roll the aircraft to the FD commanded bank angle of 25 degrees while simultaneously matching the FD pitch command.

Trials ended for a crew either after landing, or after an EEM was performed, and it was determined that the aircraft was stable and safely being reestablished into the traffic flow. The crews landed the aircraft on $25 \%$ of the trials and conducted a breakout on $75 \%$ of the trials. Each flight averaged 18 flight minutes. Crews were asked to complete a workload questionnaire after each trial and then to input the next flight plan in preparation for the next release time. Due to the dynamic nature of the insertion of the simulator into the scenario, the turnaround time from trial end to next trial start varied from 6 minutes to as long as 12 minutes. Most releases occurred approximately 6.5 minutes after a trial end. 


\section{Procedures}

Flight Crews: Crews were sent a packet to review before the experiment including an overview of the AILS concept, procedures for conducting approaches, and approach plates for SEATAC. An initial briefing was held for each crew at which the experimenters gave a brief presentation on the AILS system, an overview of the environment in which they would be flying, and provided a question and answer period to address any uncertainties that might remain. Additionally, the non-standard display features, including the traffic symbology (see Figure 3) and NAV Display zoom feature (X 10) were described. Each crew then received 1 hour of flight training conducting AILS approaches, to familiarize themselves with the display, the routing, and the execution of an emergency escape maneuver. The only modification to the normal cockpit controls in the B747-400 was the addition of the "X 10 " button on the EFIS control panel, which allowed the crew to select an expanded zoom range on the NAV Display. When the "X10" button was selected the map range was reduced 10 times, thus 10-mile range became 1mile range.

When training was completed, the crews flew 12 experimental trials, which took four to five hours. The crews then completed a debriefing questionnaire followed by a verbal question and answer session.

ATC Task: All ATC participants in the study were cohorts. Controllers from SEATAC who participated in the design of the airspace and procedures were unable to participate due to unresolved scheduling conflicts. Although SEATAC controllers did not participate in the study, they suggested that with the design of the protected airspace and approach procedures a blunder could be handled with minimal impact on ATC operations at SEATAC.

Retired controllers who were trained on the airspace and procedures manned both the feeder east and west, and final controller positions. The final controller who was to be the principal ATC subject in the study, managed in-trail separation between aircraft in each parallel approach stream and separation from other aircraft not on final approach to the parallel runways. Once the onboard surveillance and alerting system was verified and the aircraft reported on the localizer, ATC relinquished surveillance, monitoring and alerting for lateral separation to the airborne system, and the standard terminal separation for parallel traffic was no longer required. These functions are not returned to ATC unless the aircraft conducts a missed approach or breakout maneuver, and contacts ATC. This concept is similar to a TCAS resolution advisory (RA) in that once an RA occurs, the pilot has responsibility to execute the commanded maneuver, ATC loses separation responsibility and regains it only when TCAS indicates, "clear of conflict" and the pilot contacts the controller.

\section{Results}

A total of 108 trials were used for analysis, included were eleven crews that flew 10 to 12 trials each. All trials from Crews 1 and 2 were removed from the analysis due to equipment malfunction and problems with data collection and recording.

Closest Point of Approach (CPA): The closest point of approach was measured as the minimum slant range distance between the aircrafts' center of gravity. Of primary interest was the CPA between the blundering aircraft and ownship. In all cases, ownship was the aircraft remaining on the assigned approach path after the AILS alert was initiated. Several data points were removed from the analysis when it was verified that they were the result of system malfunction and in one case, system failure. Of the 100 data points included in the analysis, the closest point of approach was 352 feet, a mean CPA of 1,311 feet and the maximum CPA of 2,484 feet.

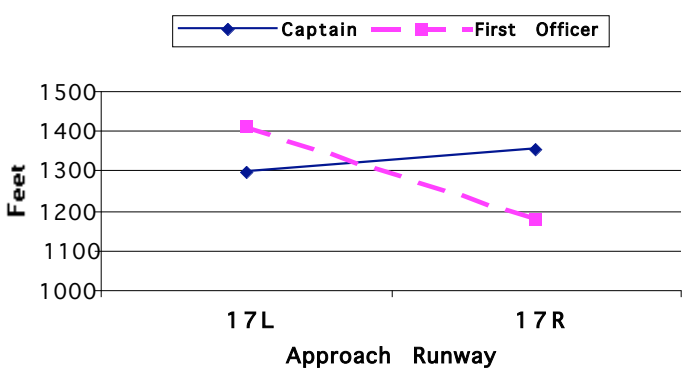

\section{Figure 6. CPA BY Crew Position And} Runway

As detailed earlier, three blunder points were designed into the arrival scenarios: early at approximately 14 miles from the threshold; midway at approximately 7 miles; and late, approximately 3 miles from the landing threshold. Each crew was assigned an equal number of breakouts at each blunder point. The mean CPA for the early blunder 
point was 1,358 feet, for the middle 1,240 feet, and the late 1,342 feet, a non-significant difference of approximately 100 feet.

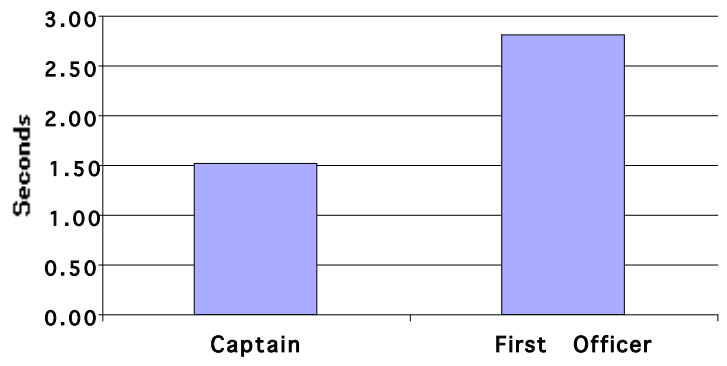

Figure 7. Response Time By Crew Position.

The closest point of approach for the pilot flying the breakout procedure - Captains or First Officers - also were not significantly different $(\mathrm{p}=0.9179)$. The mean CPA was 1,326 feet for the Captains and 1,296 feet for First Officers, a mean difference of only 30 feet.

Although no main effects of approach runway or pilot flying were found, a significant pilot flying by approach runway interaction $(\mathrm{P}=0.0449)$ was found. A post-hoc analysis showed that when First Officers were flying the approach, their CPA varied by approach runway (see Figure 6). The First Officers' CPA was significantly lower when conducting an approach to runway 17R. First Officers flew the only two approaches where less than the minimum safe distance of 500' feet was maintained.

Crew Response Time (CRT): The crew response time to the AILS alert was measured from the time the crew received a level 4 AILS alert (Turn/Climb breakout warning) until hitting either the TOGA switch or disengaging the autopilot. The mean response time to an AILS alert was 2.13 seconds with a range of 0.54 to 5.38 seconds. Overall, the Captains responded significantly faster ( $<<0.001)$ to an alert than First Officers, as indicated by their mean response times of 1.52 and 2.80 seconds, respectively. On average, Captains responded $46 \%$ faster than First Offers to an AILS breakout warning. There was also a significant main effect of crew response time by blunder location $(\mathrm{p}<0.026)$, but no significant interactions. The mean response times were $2.2,2.35$, and 1.83 seconds to the early middle and late alerts, respectively (see Figure 8).

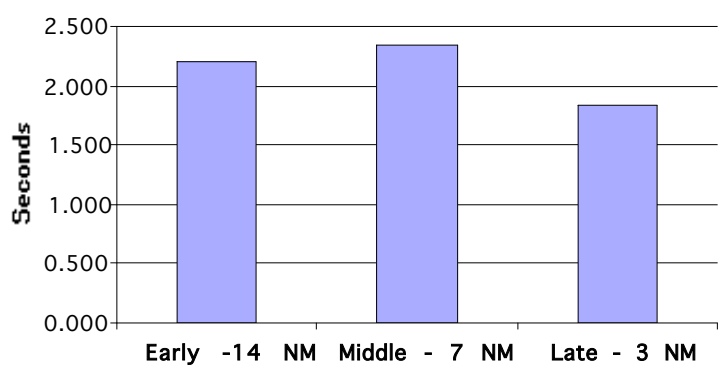

Figure 8. Crew Response Time By Blunder Location

System Response Time (SRT): System response time was measured from the time the crew hit the TOGA switch or disengaged the autopilot to the time there was a change in either speed $(0.5$ knots per second), altitude (1 foot per second) or bank angle $(+/-3 \%$ per second based on angle at time of AILS alert). The average B-747 system response time was 2.73 seconds. There was a significant difference $(\mathrm{p}<0.016)$ in the aircraft system's response times when Captains and First Officers were flying; the mean system response times were 3.18 seconds and 2.28 seconds, respectively. This difference could be due to different techniques in managing the escape maneuver, which was hand flown. There was also a significant difference in system response time by blunder point location ( $\mathrm{p}<0.52)$. A post hoc analysis showed that the difference was due to faster system response at the early blunder locations. This difference was probably due to the difference in aircraft configuration at the three locations on the arrival path. At the early blunder

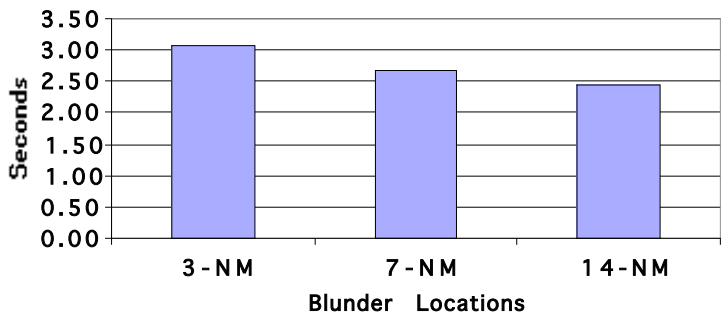

Figure 9. B-747 Response Time By Blunder Location. 
point, fourteen miles from the threshold, the aircraft is descending with minimal flaps and no landing gear. By the time the aircraft descends to the later blunder points, the flight crew starts to configure the aircraft for landing, with flaps and gear down, which would greatly increase the drag component and slow its response time considerably.

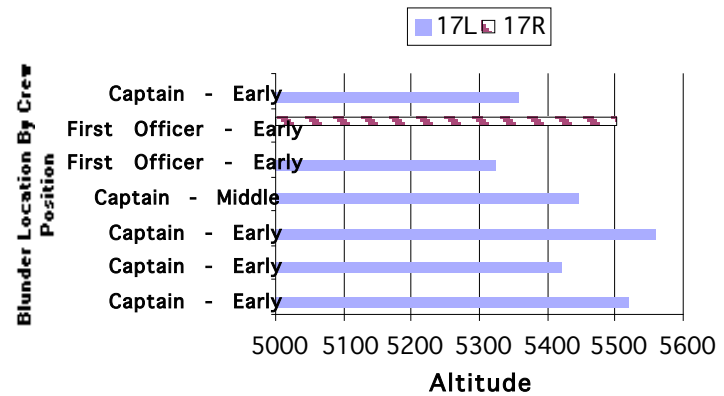

Figure 10. Altitude Bust By Blunder Location and Crew Position.

Altitude Bust During Breakout: Of all the trials flown, a small percentage $-6.4 \%(7 / 109)$ - of the crews exceeded the maximum altitude restriction of 5000 feet, listed in the approach plate break-out procedure, by more than the 300 feet limit specified in the FAA 7110.65 [11]. Of those, it can be clearly noted in the following chart (see Figure 10) that a large percentage $-72 \%(5 / 7)$ - received the AILS breakout command at the early blunder point. Their average flight profile when receiving the breakout command early in the approach was an altitude of 4,500 feet and a speed of 170 on the approach to runway $17 \mathrm{~L}$, approximately 14 miles from the threshold. Of those aircraft that did exceed 5,300 feet, the average altitude attained was approximately 5,450 feet with the maximum being 5,563 feet. It is important to remember that most of the aircraft that broke the altitude restriction $-72 \%$ $(5 / 7)$ - only had a 500 foot buffer in which to perform the breakout maneuver.

Five of the altitude busts were attributed to Captains, and only two to first Officers. It does not appear that breaking the altitude restriction had any effect on the aircraft closest point of approach (CPA). Nor does not appear that breaking the altitude restriction was the result of an unusual crew response time (CRT).

\section{Flight Crew Comments On AILS}

Flight crews were asked to provide general comments on the AILS system and provided the following feedback.

- An efforts should be made to not have $\mathrm{a} / \mathrm{c}$ abeam each other on final approach. I know that the simulation was trying to produce the worst-case situation, but ATC must try to avoid this situation to make this a safe approach.

- I like it a lot better than PRM...No descending breakouts, constant graphic monitoring - traffic display- to crew, no "big surprises", less human factors input. Only potential hazards are terrain clearance in breakout corridor, and wake turbulence of staggered traffic

- Having intercepts be at different altitudes for the two runways, coupled, at a set (modest) airspeed (which reduces turning radius/overshoot potential) should minimize problems.

- It should be an essential "emphasized" requirement that the localizer not only be tuned but confirmed as "identified" by both PF and PNF prior to establishment on intercept heading for LOC capture-this to preclude overshoot possibility.

- I couldn't imagine a scenario AILS could not handle safely.

- Adding a radar controller to monitoring aircraft position would add an additional element of safety to AILS.

- It seemed to be difficult to determine if you were getting close to the aircraft in front of you on your localizer.

- Final controller monitoring of speed and separation on the localizer would prevent a go-around due to traffic not clearing the runway.

- A system like ORD's (Chicago O'Hare) when $14 \mathrm{~L}$ and $14 \mathrm{R}$ are being used with low visibility weather would make AILS very Safe. ORD has a controller monitoring separation on the localizer and telling a flight to slow down or speed up when necessary.

- (AILS, would be OK)... If the appropriate amount of training is given.

- Just need work on ATC communication/phraseology and minor 
fine-tuning (of the system). Very easy to understand. Just a natural progression of (from standard) ILS.

- The approach itself is safe, it is the other issues of minimums, max $x$-wind component, wake turbulences, etc., that raises further concerns.

- Only problem I saw was the interaction with TCAS/AILS - twice we were given descending RA's during our climbing breakouts, probably not a great maneuver close to the ground and another aircraft in instrument conditions.

- 2500 feet is a narrow margin. With the correct equipment and responsible people this program has tremendous potential.

- Warnings are immediate and clear. ATC might not be - radio congestion, etc. Simpler, easier, than other alternatives.

- It offers adequate visual information with regard to aircraft being vectored for an approach at the airport.

- Excellent cues to the approach with paired aircraft and for deviation, cautions and breakout warnings.

- The breakout procedures and altitudes are compatible and provide adequate safety margins.

- I feel that this was a "worst case" scenario, which felt comfortable once I got accustomed to the differences.

\section{Discussions and implications}

The goals of this full mission simulation were to assess the operational feasibility of AILS from a flight crew, ATC and aircraft perspective; also to address operational questions that had not been fully addressed in previous AILS simulations. Most of the questions were related to crew and aircraft response time, transition of authority to and from the cockpit, and the impact of closely spaced parallel approach operations and multiple aircraft blunders on controllers and airspace operations at a major airport.

Although SEATAC controllers did not participate as subject controllers in the study, they suggested that with the design of the protected airspace and approach procedures a blunder could be handled with minimal impact on ATC operations at SEATAC. The design of the airspace and procedures to safely initiate the approach, the approach procedures, including the blunder and missed approach, created a seamless operation for both pilots and controllers. Controllers and flight crews reported that the roles and responsibilities were well defined and understood, and flight crews suggested that the operations could be conducted safely with slight increases in workload over the current ILS approach.

Crew response times were consistent with those found in previous research on flight crew response to alerts. The primed average response time of 2.13 seconds was faster than that found for TCAS or previous AILS studies; this was expected based on the design of the caution alerts. Since all caution alerts were followed by a breakout alert, in this study, crews were primed to respond swiftly to the breakout warning. Thus, their response times may not reflect response times during normal flight operations, where the crew of the invading parallel traffic would correct some flight deviations.

The mean aircraft system response time for the B-747 was 2.73 seconds suggesting that this aircraft does respond swiftly to flight crew inputs, even though it is one the larger aircraft in the current fleet. Additionally, as suggested by the CPA data, average flight crews responses coupled with the average aircraft responses, allowed crews to maintain and average distances of 1311 feet from blundering parallel traffic. These data also suggest that the information provided in the form of displays and aural alerts were sufficient to support this level of task performance.

The issue most closely aligned with flight safety is separation distance between the invader and evader aircraft during a blunder incident. At the closest point of approach, flight crew response time, and aircraft system response times, suggest that when flight crews are presented with airborne information on blundering parallel approach traffic, they were able to safely avoid a collision. This safety assessment is based on previous research on a controller-based, Precision Runway Monitoring System (PRM), where a criterion of 500 feet separation was considered safe, and separation distances below 500 feet were considered test criterion violations (TCV) [12]. The Pass/Fail safety criteria for PRM was a $6.8 \% \mathrm{TCV}$ rate for $100 \%$ pairs at risk operations over "N" number of trials. During the AILS full mission simulation, flight crews committed 2 TCV over 108 trials flown, or a $\sim 2 \% \mathrm{TCV}$ rate for paired at risk encounters. This rate far exceeds the safety rate for PRM, and suggest that based on this FAA approved 
criterion, conducting parallel approach operations using the AILS system and procedures would meet FAA safety standards.

Although the current AILS system evaluated during this full mission simulation meets or exceeds the PRM safety criterion, the following issues need to be addressed by further research or through flight crew and ATC training.

1. The relationship between TCAS and AILS during breakout (procedural turn and climb away from invading traffic).

2. The effect of wake turbulence on different aircraft types during breakout when proximal traffic may be as close as 350 feet.

3. The implication and impact of altitude busts on approach control operations.

4. The implications for flight deck display design of First Officer's TCV when conducting approaches to runway $17 \mathrm{R}$. Improved displays may be needed to aid in acquiring traffic on the opposite side of the aircraft.

5. Finally, additional research is needed to assess whether manual or coupled breakout procedures would best support crew responses to AILS breakout procedures.

\section{References}

[1] Radio Technical Commission for Aeronautics, 1998. Minimum Aviation Standards Performance Specification for Automatic Dependent Surveillance-Broadcast, Document RTCA DO-242 (February).

[2] Waller, M. and Scanlon, C. (editors) (1996). Proceedings of the NASA Workshop on Flight Deck Centered Parallel Runway Approaches in Instrument Meteorological Conditions, NASA Conference Publication 10191, Hampton, VA (December).

[3] Laura L. Rine, Terence S. Abbott, Gary W. Lohr, Dawn M. Elliott, Marvin C. Waller and R. Brad Perry, The Flight Deck Perspective of the NASA Langley AILS Concept, NASA/TM-2000209841, January 2000, pp. 50, (787KB).

[4] Samanant, P, Jackson, M., Haissig, C., and Corwin, B. (2000). "CASPER/AILS: An Integrated DGPS/ADS-B Airborne Alerting System for Closely Spaced Parallel Approaches", AIAA/IEEE PLANS Conference, March 2000.
[5] Jackson, M., Samanant, P., and Haissig, C. (2000). "Design and Analysis of Airborne Alerting Algorithms for Closely-Spaced Parallel Approaches," AIAA GN\&C Conference, August 2000.

[6] Haissig, C., Corwin, B., Jackson, M.,. (1999). "Designing an Airborne Alerting System for Closely-Spaced Parallel Approaches," Paper AIAA99-3986, AIAA GN\&C Conference, San Diego, CA, August 2000.

[7] Kuchar, J. (1996). "Methodology for AlertingSystem Performance Evaluation," J. of Guidance, Control, and Dynamics, 19(2).

[8] Carpenter, B., and Kuchar, J. (1997). "Probability-Based Collision Alerting Logic for Closely-Spaced Parallel Approach," Paper AIAA97-0222. AIAA Aerospace Sciences Meeting and Exhibit, Reno, NV (January).

[9] Johnson, W.W., Battiste, V., and Holland, S. (1999). A cockpit display designed to enable limited flight deck separation responsibility.

Proceeding of the 1999 World Aviation Conference, Anaheim, CA.

[10] Federal Aviation Administration, 1991. Precision Runway Monitor Demonstration Report. Document DOT/FAA/RD-91/5.

[11] Federal Aviation Administration 7110.65L Air Traffic Control, February 26, 1998.

[12] Ladecky, S. (1999). AILS/PRM Comparative Study. Final Report, FAA: Oklahoma City, OK 